\title{
Neuroplastic Changes Related to Pain Occur at Multiple Levels of the Human Somatosensory System: A Somatosensory-Evoked Potentials Study in Patients with Cervical Radicular Pain
}

\author{
Michele Tinazzi, ${ }^{1}$ Antonio Fiaschi, ${ }^{1}$ Tiziana Rosso, ${ }^{1}$ Franco Faccioli, ${ }^{2}$ Johannes Grosslercher, ${ }^{2}$ and \\ Salvatore M. Aglioti $^{3}$ \\ Dipartimenti di Scienze Neurologiche e della Visione, ${ }^{1}$ Sezione di Neurologia Riabilitativa and 2 Sezione di Neurochirurgia, \\ Università di Verona, 37134 Verona, Italy, and "Dipartimento di Psicologia, Università di Roma "La Sapienza," and Istituto di \\ Ricovero e Cura a Carattere Scientifico, Fondazione Santa Lucia, 00179 Rome, Italy
}

\begin{abstract}
Studies suggest that pain may play a major role in determining cortical rearrangements in the adult human somatosensory system. Most studies, however, have been performed under conditions whereby pain coexists with massive deafferentation (e.g., amputations). Moreover, no information is available on whether spinal and brainstem changes contribute to pain-related reorganizational processes in humans. Here we assess the relationships between pain and plasticity by recording somatosensoryevoked potentials (SEPs) in patients who complained of pain to the right thumb after a right cervical monoradiculopathy caused by compression of the sixth cervical root, but did not present with clinical or neurophysiological signs of deafferentation. Subcortical and cortical potentials evoked by stimulation of digital nerves of the right thumb and middle finger were compared with those obtained after stimulation of the left thumb and middle finger and with those obtained in a control group tested in comparable
\end{abstract}

conditions. Amplitudes of spinal N13, brainstem P14, parietal N20 and P27, and frontal N30 potentials after stimulation of the painful right thumb were greater than those of the nonpainful left thumb and showed a positive correlation with magnitude of pain. This right-left asymmetry was absent after stimulation of the patients' middle fingers and in control subjects. Results suggest that chronic cervical radicular pain is associated with changes in neural activity at multiple levels of the somatosensory system. The absence of correlation between the amplitude of spinal, brainstem, and cortical components of SEPs suggests that enhancement of cortical activity is not a simple amplification of subcortical enhancement.

Key words: pain; upper limb SEPs; somatosensory-evoked potentials; somatosensory system; deafferentation; brain plasticity; cervical radiculopathy
Studies in animals and humans show somatosensory cortical reorganization induced by pathological perturbations of the peripheral input (Merzenich et al., 1983a,b; Pons et al., 1991; Elbert et al., 1994; Rossini et al., 1994; Yang et al., 1994; Florence and Kaas, 1995; Tinazzi et al., 1997). In monkeys that had undergone an extended dorsal rhizotomy, it has been shown that cortical territories formerly mapping the deafferented skin regions were driven by inputs coming from adjacent intact regions (Pons et al., 1991). This remapping process may have to do with the enhancement of cortical activity evoked by stimulating cutaneous territories adjacent to deafferented arms in amputees (Elbert et al., 1994; Yang et al., 1994) and in patients with peripheral deafferentation (Rossini et al., 1994; Tinazzi et al., 1997, 1998). Research in animals has demonstrated that neuroplastic changes induced by peripheral deafferentation also occur in subcortical structures such as the dorsal horn, the nucleus cuneatus, or the somatosensory thalamus (Pettit and Schwark, 1993; Florence and Kaas, 1995; Faggin et al., 1997; Jain et al., 2000). Reorganization in the thalamus (Davis et al., 1998), or even at multiple levels of the somatosensory system (Tinazzi et al., 1998), has also been recently reported in human patients with a chronic, severe deafferentation.

The possible role of pain in promoting cortical reorganization has been recently reported in humans (Flor et al., 1995, 1997; Birbaumer et al., 1997). Magnetoencephalography studies in am-

Received July 5, 2000; revised Sept. 5, 2000; accepted Sept. 27, 2000.

This research was supported by grants from the Centro di Riabilitazione Polifunzionale, Zevio (Verona), the Consiglio Nazionale delle Ricerche and the Ministero dell'Università e della Ricerca Scientifica e Tecnologica, Rome, Italy. We thank Dr. A. Polo, R. Marconi, and S. Ferrari for technical assistance.

Correspondence should be addressed to M. Tinazzi or S. M. Aglioti, Dipartimento di Scienze Neurologiche e della Visione, Sezione di Fisiologia Umana, Università di Verona, Strada Le Grazie, 8, 37134, Verona, Italy. E-mail: smagli@borgoroma.univr.it. Copyright (C) 2000 Society for Neuroscience $0270-6474 / 00 / 209277-07 \$ 15.00 / 0$ putee patients with phantom limb pain show that the amount of cortical reorganization is positively correlated to the magnitude of pain experienced by the subjects (Flor et al., 1995). A strong functional link between cortical reorganization and phantom limb pain is also suggested by the fact that suppressing phantom pain with regional anesthesia brought about a clear reduction of cortical reorganization (Birbaumer et al., 1997). This would suggest that both the removal of afferent inputs and the enhanced nociceptive inputs contribute to neural reorganization.

Here we address two main issues: (1) whether ongoing pain stimulation per se may lead to reorganizational processes within the somatosensory pathway; and (2) at what level this pain-related modulation takes place. With this aim, we tested patients who presented with chronic pain in the absence of clinical and electrophysiological signs of deafferentation. Spinal, brainstem, and cortical somatosensory-evoked potentials (SEPs) were recorded in patients with unilateral cervical radiculopathy [involving the sixth cervical root (C6)] by stimulation of the digital nerves of the painful right thumb and the nonpainful left thumb and middle fingers on both sides. Unlike magnetoencephalography, the SEP recording technique offers the unique opportunity to assess neural activity not only of different cortical somatosensory areas but also of dorsal horn and dorsal column-lemniscus medialis systems, and thus to evaluate neural changes at multiple levels in the somatosensory pathway.

\section{MATERIALS AND METHODS}

Subjects. We studied 10 right-handed patients (4 women and 6 men), ages 38-54 years (mean, 45.9; SD, 5.2), who showed clinical and magnetic resonance evidence for protrusion of an intervertebral disk that compressed the right sixth cervical root. Relevant demographical and clinical information is provided in Table 1.

In all patients, the clinical picture was highly compatible with compression at the level of C6 (Yoss et al., 1957; Hoppenfield, 1976; Schimsheimer 
Table 1. Clinical and demographical data of patients with right monoradiculopathy at C6

\begin{tabular}{|c|c|c|c|c|c|c|c|c|c|c|}
\hline \multirow[b]{2}{*}{ Patient } & \multirow{2}{*}{$\begin{array}{l}\text { Age } \\
\text { (years) }\end{array}$} & \multirow[b]{2}{*}{ Sex } & \multirow{2}{*}{$\begin{array}{l}\text { McGill Pain } \\
\text { Questionnaire }\end{array}$} & \multicolumn{5}{|c|}{ Pain referred to } & \multicolumn{2}{|c|}{ Paraesthesias to } \\
\hline & & & & Thumb & Index finger & Arm & Shoulder & Neck & Thumb & Index finger \\
\hline 1 & 48 & M & 33 & + & + & - & + & - & + & + \\
\hline 2 & 38 & M & 53 & + & - & - & - & - & - & - \\
\hline 3 & 45 & M & 40 & + & - & + & + & + & + & - \\
\hline 4 & 40 & M & 40 & + & + & - & - & - & - & - \\
\hline 5 & 44 & M & 37 & + & + & + & + & + & + & + \\
\hline 6 & 51 & $\mathrm{~F}$ & 33 & + & - & - & - & - & + & - \\
\hline 7 & 41 & $\mathrm{~F}$ & 43 & + & - & + & + & - & - & - \\
\hline 8 & 48 & $\mathrm{~F}$ & 50 & + & + & - & + & - & + & + \\
\hline 9 & 50 & $\mathrm{~F}$ & 56 & + & - & - & - & - & + & - \\
\hline 10 & 54 & M & 51 & + & + & + & + & - & - & - \\
\hline
\end{tabular}

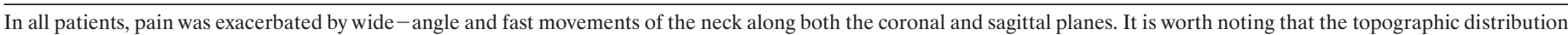
of pain mainly reflects the level of the compression (C6 root). The plus $(+)$ and minus $(-)$ indicate presence or absence of pain or paraesthesias.

et al., 1988). Relevant to the purposes of the present study is the fact that although all patients complained of pain to the right thumb (reflecting involvement of the $\mathrm{C} 6$ root), none of them reported pain involving the right middle finger (reflecting involvement of the $\mathrm{C} 7$ root). In all patients, pain had started 30-90 d before the experimental tests. Seven of the 10 patients had undergone periods of treatment with antipyretic analgesics. At the time of testing, however, these patients had not been treated for at least $5 \mathrm{~d}$. Subjective experience of pain was assessed by the Italian version of the McGill Pain Questionnaire (Melzack, 1975; Maiani and Sanavio, 1985). Most patients reported that pain typically started suddenly, often on awakening. From a qualitative point of view, pain was described as burning, piercing, and squeezing by most patients. The feeling of "pins and needles" in the right thumb (or the index finger) was also commonly reported. The topographic distribution of paraesthesias originating from the painful territory is shown in Table 1 .

No patient presented with clinical or electromyography (EMG) evidence of deficits in the painful territory. Clinical examination of motor and somatic function of the body parts innervated by the C6 root was based on comparisons of the right and left sides in the following tests. (1) Motor function was assessed by evaluating muscle strength of biceps brachii and brachioradialis muscles on the two sides. Moreover, stretch reflexes for biceps brachii and supinator muscles were assessed. (2) Somatic function was assessed by delivering through blunt pins a series of brief, light touches on the left and right thumbs and asking subjects to report any difference between the two sides. This procedure was repeated by delivering stimuli on the right thumb and middle finger. No differences between the right and left sides (and the right thumb and middle finger) were detected in any of the tests. It is relevant that clinical examination was performed by trained neurologists who were not aware of the aims of the study.

The EMG study was conducted according to standard procedures (Kimura, 1989) and focused on the muscles innervated by the C6 root. Biceps brachii and brachioradialis muscles did not show any spontaneous activity, and the recruitment pattern was normally interferential. The minimum latency of F-waves from median and ulnar nerves was also normal. Motor-action potentials evoked by stimulation of the median nerve and recorded over the abductor pollici brevis were normal in latency and amplitude. Finally, sensory action potentials evoked by antidromic stimulation of the ulnar, median, and radial nerves and recorded over the five fingers were normal in latency and amplitude.

Additional values of tactile and pain sensitivity were also obtained in each subject by means of electric stimuli similar to those used in subsequent SEP recording sessions. Stimuli were delivered through ring electrodes positioned on the first or third finger on either the left or right hand. Thus, each subject was tested in four blocks. The lowest intensity used in each subject was $1 \mathrm{~mA}$. A series of stimuli with intensity increasing in steps of $0.1 \mathrm{~mA}$ were delivered. Subjects were requested to report whether they perceived any stimulation. The intensity value of the first stimulus perceived was adopted as a measure of tactile sensitivity (TS). After TS was measured, stimuli with intensity increasing in steps of $0.4 \mathrm{~mA}$ were used. In each trial, subjects were asked to report whether the stimulus was painful. The intensity value of the first stimulus perceived as painful was adopted as a measure of sensitivity to pain (SP). The duration of each stimulus was $0.2 \mathrm{msec}$, i.e., identical to that used during subsequent SEP recording sessions. The order in which fingers were stimulated (first or third, left or right) was counterbalanced across the different subjects.

Ten right-handed healthy individuals (five women and five men) matched for age (range, 31-50 years; mean, 43.3; SD, 6.2) served as a control group. All subjects were right-handed, as ascertained by using the Oldfield questionnaire (Oldfield, 1971). All subjects gave written, informed consent for participation in the study, and the protocol was approved by the local ethical committee.

SEP recording procedure. During SEP recording sessions, subjects lay supine on a comfortable bed in a quiet room. Special attention was paid to the patients' head position, with the aim of avoiding pain triggered by movements of the neck. SEPs were recorded by using an Esaote Biomedica Reporter (Esaote Biomedica, Florence, Italy). Recording electrodes (with impedance below $5 \mathrm{k} \Omega$ ) were placed over the spinous process of the sixth cervical vertebra (Cv6) [referred to as the anterior neck (AC)], and in the parietal and frontal scalp regions contralateral to stimulation (P3, P4, and F3, F4) with an electrode reference located at the earlobe ipsilateral to the stimulation site.

The bandpass was $5-1500 \mathrm{~Hz}(-3 \mathrm{~dB}$ at the cutoff point, $6 \mathrm{~dB}$ per octave), with an analysis time of $100 \mathrm{msec}$ and a bin width of $103 \mu \mathrm{sec}$. Stimuli were electrical square pulses of $0.2 \mathrm{msec}$ duration delivered through ring electrodes over the digital nerve of the first and third fingers of both hands at a repetition rate of $2.3 \mathrm{sec}$. The ring electrodes (with impedance below $5 \mathrm{k} \Omega$ ) were positioned on the first and second phalanx of the thumb and middle finger. The cathode was $20 \mathrm{~mm}$ proximal to the anode. The skin areas underlying the electrodes were cleaned with acetone, and conductive paste was applied on them. Intensity of the stimuli was $3 \times$ the TS value, and in no case was this reported as painful. Samples with excess interference were automatically rejected from the average. A total of 800 sweeps were averaged. Each test was repeated at least twice to confirm the reproducibility. Summated tracings of two repeatable averages were used for amplitude and latency measurements (Tinazzi et al., 2000). To ensure full muscle relaxation, muscular activity was monitored through surface EMG recording from the flexor muscles of the arm on the stimulated side.

Table 2. Mean $( \pm$ SD) values (in milliamperes) of tactile and pain sensitivity in the experimental and control groups

\begin{tabular}{|c|c|c|c|c|}
\hline & \multicolumn{2}{|l|}{ Patients } & \multicolumn{2}{|l|}{ Controls } \\
\hline & Tactile & Pain & Tactile & Pain \\
\hline \multicolumn{5}{|l|}{ Right } \\
\hline Thumb (painful) & $3.8(0.8)$ & $19.8(3.9)$ & $3.7(0.8)$ & $20.8(3.6)$ \\
\hline Middle finger & $3.6(0.5)$ & $19.1(3.4)$ & $3.4(0.4)$ & $19.2(3.2)$ \\
\hline \multicolumn{5}{|l|}{ Left } \\
\hline Thumb & $3.5(0.9)$ & $20.2(4.3)$ & $3.4(0.7)$ & $20.2(4.4)$ \\
\hline Middle finger & $3.5(0.7)$ & $18.8(3.2)$ & $3.5(0.7)$ & $18.8(3.6)$ \\
\hline
\end{tabular}


Table 3. Amplitude values (in microvolts) of the subcortical and cortical SEP components obtained in response to stimulation of digital nerves of the thumb and middle finger in the experimental groups

\begin{tabular}{|c|c|c|c|c|c|c|c|c|}
\hline \multirow[b]{3}{*}{ SEP } & \multicolumn{4}{|l|}{ Patients } & \multicolumn{4}{|l|}{ Controls } \\
\hline & \multicolumn{2}{|l|}{ Right } & \multicolumn{2}{|l|}{ Left } & \multicolumn{2}{|l|}{ Right } & \multicolumn{2}{|l|}{ Left } \\
\hline & Thumb (painful) & Middle finger & Thumb & Middle finger & Thumb & Middle finger & Thumb & Middle finger \\
\hline N13 & $1.0(0.4)$ & $0.8(0.2)$ & $0.7(0.3)$ & $0.8(0.1)$ & $0.7(0.2)$ & $0.8(0.2)$ & $0.7(0.2)$ & $0.7(0.3)$ \\
\hline $\mathrm{P} 14$ & $0.4(0.2)$ & $0.5(0.3)$ & $0.3(0.2)$ & $0.5(0.3)$ & $0.4(0.1)$ & $0.4(0.3)$ & $0.4(0.1)$ & $0.4(0.4)$ \\
\hline $\mathrm{N} 20$ & $1.7(0.4)$ & $1.2(0.4)$ & $1.3(0.3)$ & $1.3(0.4)$ & $1.3(0.4)$ & $1.4(0.5)$ & $1.3(0.5)$ & $1.3(0.5)$ \\
\hline P27 & $1.6(0.7)$ & $1.2(0.4)$ & $1.1(0.4)$ & $1.3(0.4)$ & $1.3(0.5)$ & $1.4(0.4)$ & $1.2(0.5)$ & $1.3(0.4)$ \\
\hline N30 & $1.8(0.6)$ & $1.5(0.5)$ & $1.4(0.5)$ & $1.5(0.7)$ & $1.4(0.4)$ & $1.5(0.3)$ & $1.4(0.3)$ & $1.5(0.4)$ \\
\hline
\end{tabular}

Values in parentheses indicate SDs.

The following components were identified: the N13 potential, recorded at Cv6 originating in the dorsal horn of the cervical spinal cord (Desmedt and Cheron, 1981), which is preceded by the peripheral P9 far-field potential arising from the brachial plexus (Desmedt and Cheron, 1981); the far-field P14 potential, recorded over the parietal and frontal electrodes, which originates from the nucleus cuneatus (Desmedt and Cheron, 1981); the N20 and P27 potentials, recorded over the parietal region contralateral to the stimulation side, which are thought to arise from primary somatosensory cortex (Desmedt et al., 1987; Allison et al., 1991); and the N30 potential, recorded over the contralateral frontal region, which probably originates from multiple generators located in the frontal lobe (Mauguière et al., 1983; Desmedt et al., 1987) and in the posterior wall of the central sulcus (Allison et al., 1991). Amplitudes were measured from the preceding peak (peak-to-peak), and latencies were measured at the peak of each component. Within-group comparisons were performed on absolute amplitude values of SEPs, whereas between-group comparisons were performed on the side-to-side ratios of SEP components evoked by stimulation of the right $(\mathrm{R})$ and the left $(\mathrm{L})$ side: $\mathrm{R} / \mathrm{L}^{*} 100$. It is worth noting that the procedure of ratio extraction is recommended for reducing amplitude variability between individuals of different groups (Mauguière and Desmedt, 1988).

Statistical analysis. Statistical analyses were performed by using nonparametric tests that are adept at controlling for possible violations of homogeneity of variance and effects of non-normal distributions. The unpaired Mann-Whitney test was used for contrasting tactile and pain sensitivity values with amplitude and peak latencies obtained by stimulating thumb and middle fingers on each side in patients versus controls. The paired Wilcoxon test was used for comparing tactile and pain sensitivity values and SEP component values obtained by stimulation of the right thumb and middle finger with those obtained by stimulation of the left thumb and middle finger. The Spearman rank order correlation coefficient was used for assessing possible relationships between two factors: (1) the side-toside ratio of amplitudes for the subcortical (spinal N13 and brainstem P14) and cortical SEP components (parietal N20, P27, and frontal N30); and (2) the side-to-side ratio of amplitudes of each SEP component with scores obtained using the McGill Pain Questionnaire evaluating characteristics of pain, with time since onset of symptoms and with the presence of paraesthesias. The $\alpha$ level for significance was set at $p<0.05$. Values in the text are given in the form of mean $\pm \mathrm{SD}$.

\section{RESULTS}

\section{Psychophysical tests}

Tactile and pain sensitivity values in patients and controls are reported in Table 2. No significant differences in the pain and tactile sensitivity values were detected when comparing the first and third fingers of the right and left hands in the two groups.

\section{Neurophysiological findings}

Mean amplitudes for the different SEP components in patients and controls are reported in Table 3 . It appears that stimulation of the patients' painful right thumbs evoked spinal N13, brainstem P14, and cortical N20, P27, and N30 potentials with amplitudes significantly larger than those evoked by stimulation of the nonpainful left thumbs (Wilcoxon test, $p<0.05$ ). No such right-left asymmetry was observed in patients after stimulation of the middle fingers.

In the control group, there were no right-left differences in SEP components evoked by stimulation of the thumb or the middle finger. It is particularly relevant that the P9-N13 interpeak value, a functional marker of the somatosensory pathway from the plexus to the dorsal horn, was not different in patients and controls. The
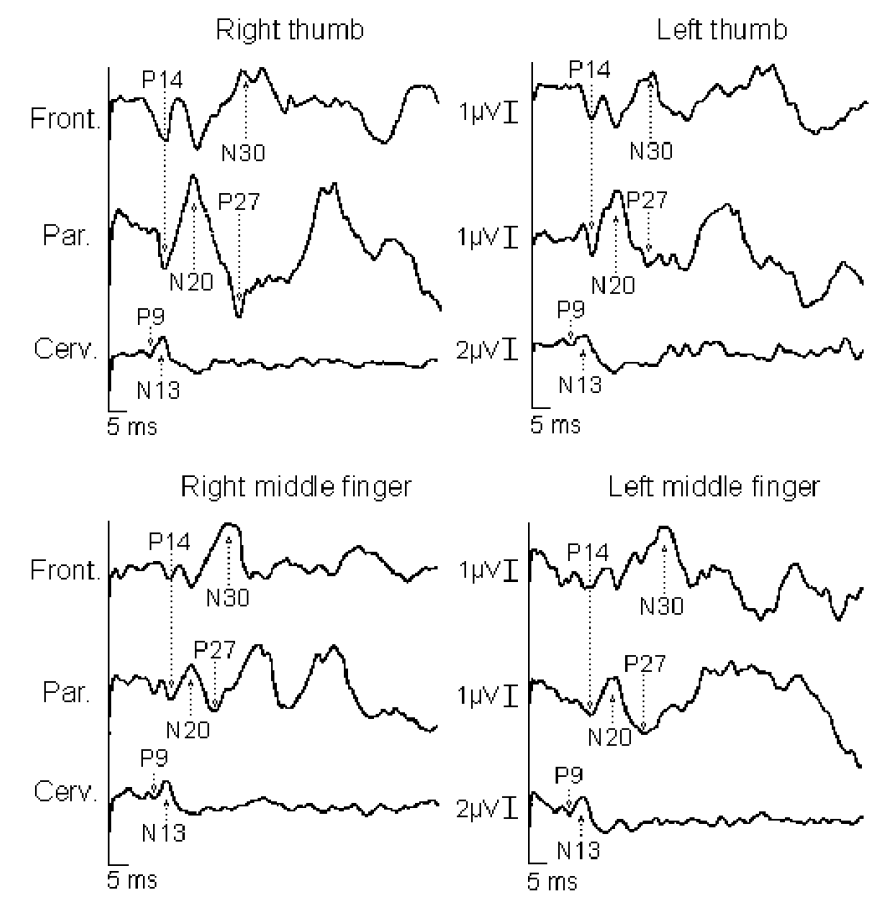

Figure 1. Somatosensory-evoked potentials to right and left digital nerve stimulation of the thumb and middle fingers in patient 2 . The spinal N13, brainstem $P 14$, cortical N20, P27, and N30 potentials evoked to stimulation of the right thumb (painful) are greater in amplitude than those to stimulation of the left thumb (nonpainful). No such asymmetry was detected after stimulation of the middle, nonpainful fingers. It is relevant that the $P 9$ potential is similar between the two sides.

profile of the different SEP components in two representative patients and one control subject is reported in Figures 1, 2, and 3.

\section{Ratio of right-left amplitudes of SEP components}

Figure 4 reports the right-to-left amplitude ratio of the different central SEP components evoked by stimulation of the thumb or the third finger in patients and controls. The mean right-to-left amplitude ratio of all central SEP components obtained by stimulation of the thumb of spinal, brainstem, and cortical responses was significantly greater in patients than in the control group. In contrast, the right-to-left ratio of the peripheral P9 component was not different in patients and controls, thus indicating that the increased electrical activity in the somatosensory pathway originated at a central rather than a peripheral level. No significant SEP differences were observed between patients and control subjects when the third finger was stimulated (Fig. 4).

\section{Regression analyses}

As previously reported, both subcortical (spinal N13 and brainstem P14) and cortical SEP components (parietal N20, P27, and frontal 

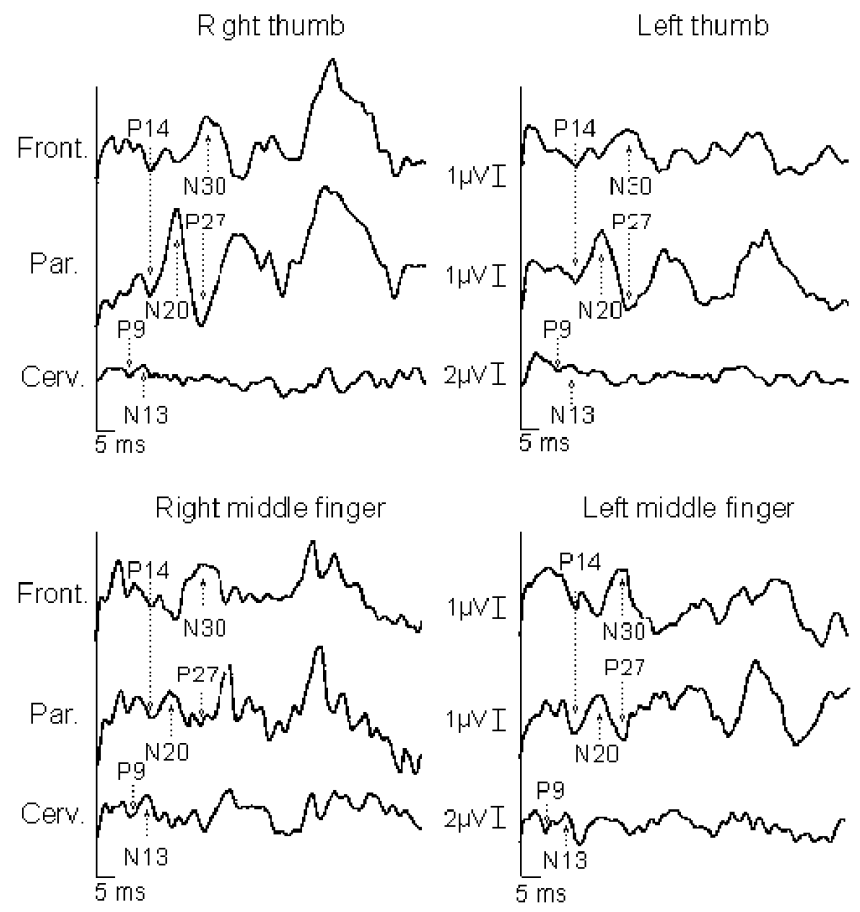

Figure 2. Somatosensory-evoked potentials to right and left digital nerve stimulation of the thumb and middle fingers in patient 9 . The pattern of results is analogous to that reported in the legend of Figure 1.
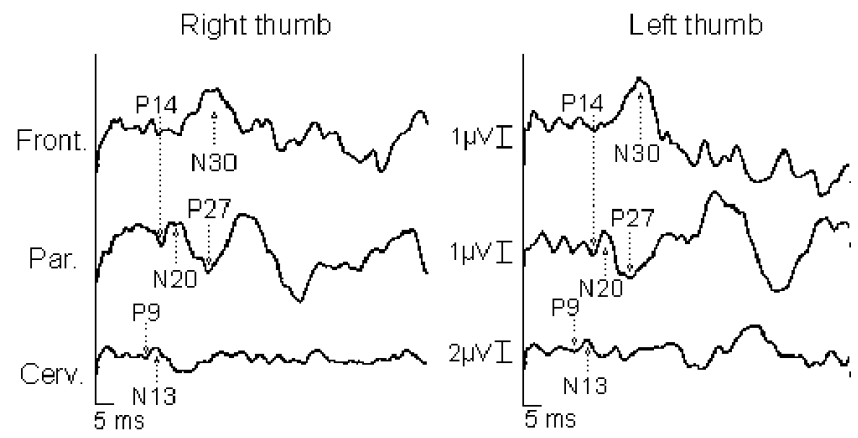

Right middle finger

Left middle finger
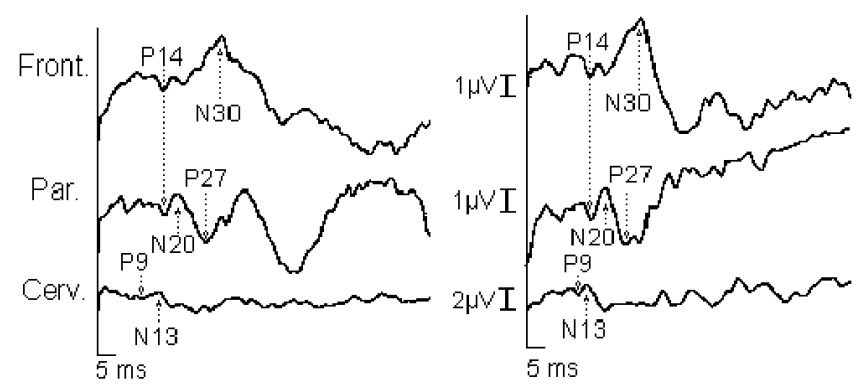

Figure 3. SEPs to right and left digital nerve stimulation of the thumb and middle fingers in a control subject. The N13 potential was recorded with a Cv6-AC montage. It is preceded by a $P 9$ far-field potential reflecting the activity of the brachial plexus. Over the scalp, the $N 20$ potential recorded over the parietal electrodes (P3 and P4) contralateral to the stimulation side was preceded by a P14 potential and followed by a large $P 27$ potential. The $N 20$ potential exhibited a reversed-phase $P 20$ potential over the frontal electrodes (F3 and F4), followed by a large negativity ( $N 30$ potential). It is worth noting that the spinal N13, brainstem P14, cortical N20, P27, and N30 potentials evoked to stimulation of the right thumb and middle finger are similar in amplitude with respect to those to stimulation of the left thumb and middle finger.

\section{DCONTROLS \\ DPATIENTS}

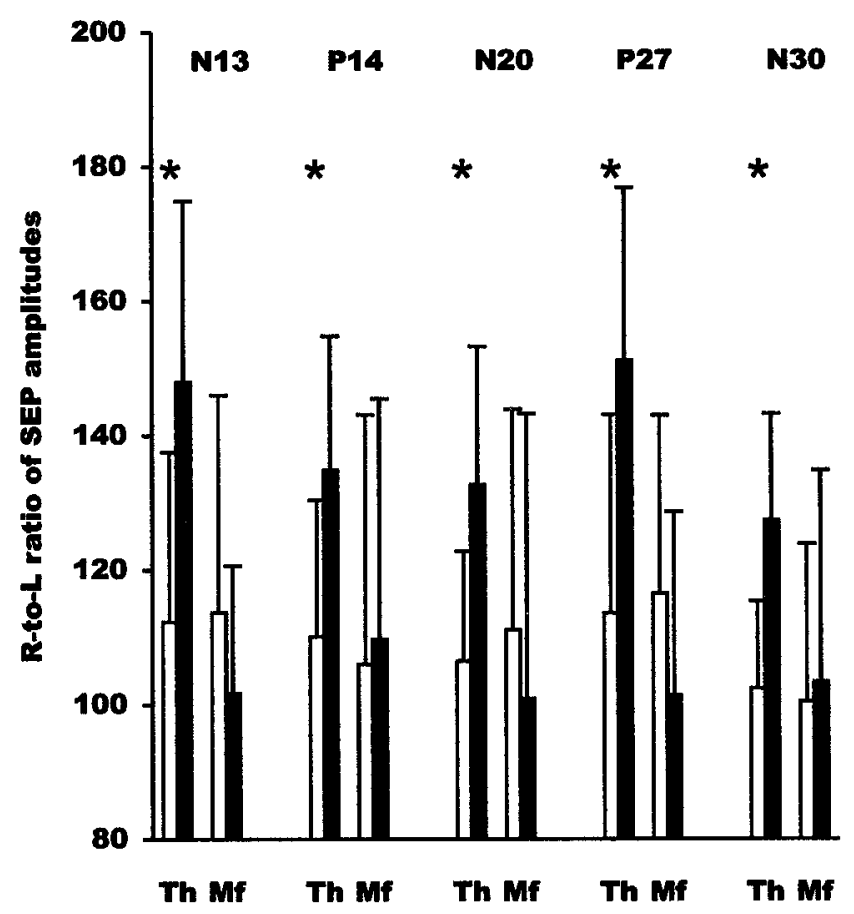

Figure 4. Right-to-left ratio (R/L*100) of amplitudes of N13, P14, N20, $P 27$, and N30 potentials obtained by stimulation of the thumb $(T h)$ and middle finger $(M f)$ in patients and controls. Error bars indicate SDs. Significant comparisons are marked by asterisks.

N30) were greater when evoked by stimulation of the painful right thumb than when evoked by stimulation of the nonpainful left thumb. However, no correlation between differences of amplitude of subcortical (spinal N13 and brainstem P14) and cortical (N20, $\mathrm{P} 27$, and N30) potentials evoked by stimulation the first finger was observed. (Spearman's correlation values for N13 were $\rho=0.26$ with N20; $\rho=0.42$ with P27; and $\rho=0.26$ with N30. Correlation values for P14 were $\rho=0.06$ with N20; $\rho=0.31$ with P27; and $\rho=$ 0.43 with N30.) This result would suggest that the enhancement of cortical responses is largely independent from the enhancement of spinal and brainstem components. The affected/unaffected ratio of amplitude of central SEP components showed a significant positive correlation with the magnitude of pain as inferred from scores in the McGill Pain Questionnaire (Fig. 5, scatter plots). No correlation was found between amplitude of SEP components and duration of pain, presence of paraesthesias, and values of tactile and pain sensitivity.

\section{DISCUSSION}

Neuroplastic changes induced by pain have been demonstrated in animals. Studies suggest, for example, that intense noxious stimulation or tissue injury can produce dramatic changes in sensitivity to both noxious and non-noxious stimulation as well as expansion of the receptive fields of neurons of the dorsal horn (Perl et al., 1976; Price et al., 1978; Kenshalo et al., 1979, 1982; McMahon and Wall, 1984; Woolf and King, 1990; Simone et al., 1991; Dougherty and Willis, 1992; Coderre et al., 1993). Sensitization and expansion of receptive fields in response to inflammation and tissue injury or electrical nerve stimulation have also been demonstrated in the thalamus (Guilbaud et al., 1986) and somatosensory cortex (Lamour et al., 1983).

Only recently has it been suggested that pain may play a crucial 

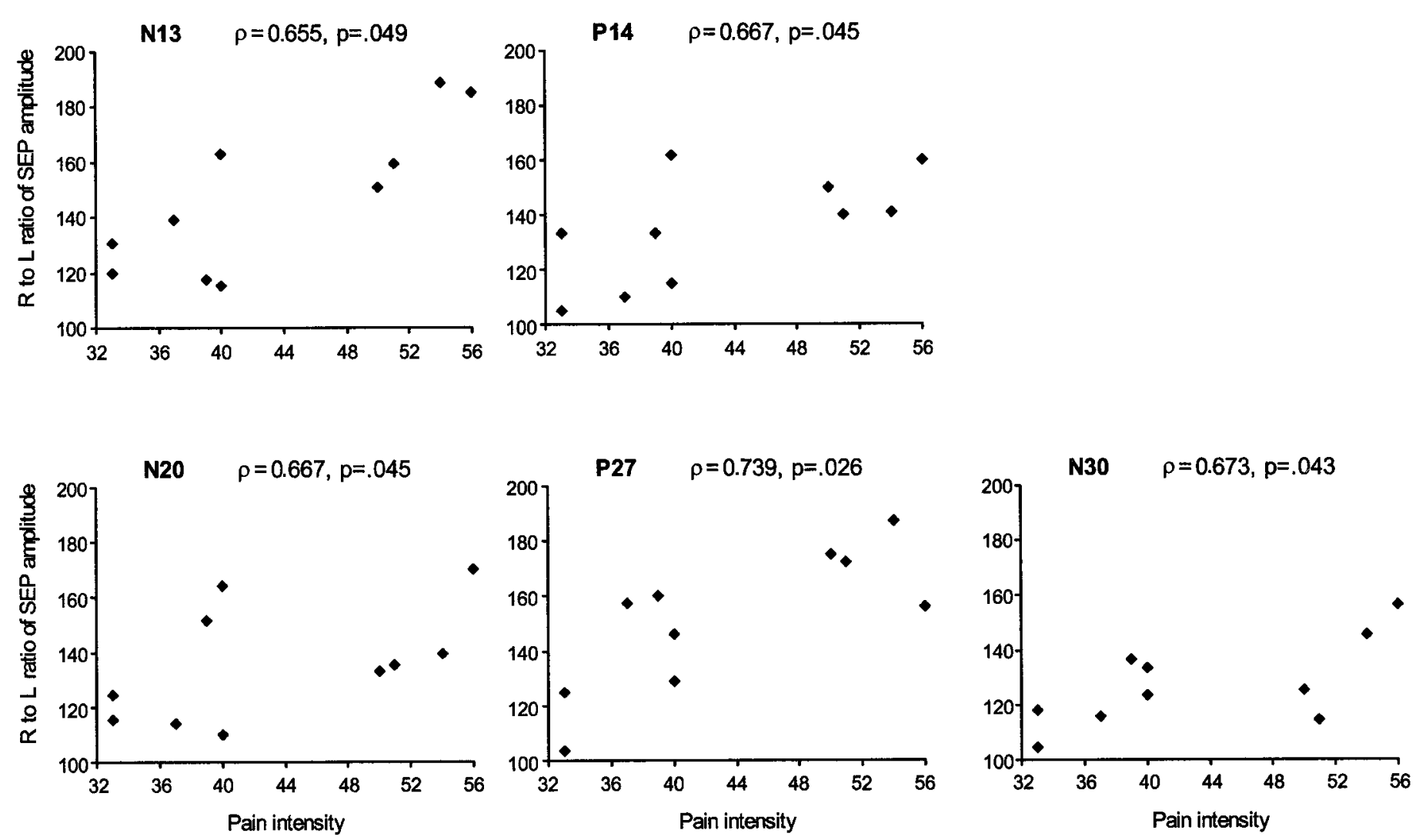

Figure 5. Scatter plots showing the Spearman rank correlation between measures of pain intensity with right-to-left ratio (R/L*100) of amplitudes of $N 13$, $P 14, N 20, P 27$, and $N 30$ potentials obtained by stimulation of the thumb.

role in promoting cortical reorganization in humans (Flor et al., 1995, 1997; Birbaumer et al., 1997). Magnetoencephalography studies in amputee patients with phantom limb pain show a positive correlation between neuromagnetic indices of cortical reorganization and subjective reports of the intensity of phantom pain (Flor et al., 1995). The notion of a close relationship between cortical reorganization and phantom limb pain is also supported by a study in which the suppression of phantom pain with regional anesthesia brought about a clear reduction of neuromagnetic markers of cortical reorganization (Birbaumer et al., 1997). Finally, a strong correlation between shifts in the cortical position of the magnetic dipole evoked by somatic stimulation and the magnitude of pain was reported in patients with chronic back pain (Flor et al., 1997). In these studies, however, pain coexisted with deafferentation that is known to promote neuroplastic changes per se (Florence and Kaas, 1995).

\section{Pain-related enhancement of neural activity in the somatosensory system}

An important result of this study is that amplitudes of spinal (N13), brainstem (P14), and cortical (N20, P27, and N30) SEPs to stimulation of the patients' painful right thumb were greater than those recorded in response to stimulation of the nonpainful left thumb and those recorded in controls. This right-left difference in amplitude was not observed after stimulation of the nonpainful third fingers. Thus, the increased excitability of spinal, brainstem, and cortical structures is specific to the painful region. Clinical examinations showed that tactile perception sensitivity measures were not different in the first painful finger and the nonpainful fingers. Moreover, the peak-to-peak latency of the P9-N13 (which is an index of activity in the segment of the somatosensory pathway from brachial plexus to dorsal horn) was not different on the intact and affected side. Although the presence of subclinical deafferentation resulting from compressive damage of tactile afferents cannot be conclusively ruled out, clinical and neurophysiological indices would suggest that deficits involving large-diameter fibers of the painful territory are minor or absent in our patients. The fact that high-amplitude SEP components evoked by stimulation of the painful territory were not related to any change of tactile and pain sensitivity in that territory may appear puzzling. This lack of relationship, however, may suggest that the SEP technique is sensitive enough to detect physiopathological modifications before the appearance of clinical symptoms.

Amplitudes of SEPs did not correlate with the presence of paraesthesias, thus indicating that these positive perceptual phenomena cannot account for the observed subcortical and cortical enhancement. By contrast, a significant, positive correlation between the amplitudes of central SEPs to stimulation of the painful thumb and the magnitude of subjective measures of pain intensity was detected, suggesting that the increased amplitudes of central SEPs reported above are likely to be related to pain per se.

This finding is a significant extension of previous work on amputee subjects in whom pain coexisted with a massive deafferentation (Flor et al., 1995; Birbaumer et al., 1997) or on back pain patients in whom the degree of deafferentation was not specified (Flor et al., 1997). Our neurophysiology results are also in keeping with a recent behavioral study reporting that acute pain per se may induce mislocation phenomena even in intact humans (Knecht et al., 1998). These authors applied acute pain to the hand, followed by non-noxious tactile stimulation of the ipsilateral lip, and serendipitously found that subjects reported phantom-like sensations on the hand synchronous to the lip stimulation. Given the representational contiguity of lip and hand in the somatosensory system, phantom-like sensations may indicate that painful stimuli perchance unmask silent connections between neural regions mapping these two body parts.

Another novel point in this study is that pain induces an in- 
creased neural reactivity to tactile input coming from the very same painful skin territory. This suggests that plastic changes can occur across different somatic submodalities subserving the same cutaneous territory.

\section{Neural loci of plastic changes related to pain}

Unlike magnetoencephalography, which allows one to explore neuromagnetic activity in the cortex, the technique of SEP allows us to assess the function of the somatosensory pathway at spinal, brainstem, and cortical levels. Although neurophysiology studies suggest that thalamic structures significantly modulate pain-related cortical changes (Guilbaud et al., 1986; Katz et al., 1999), the present study cannot add to this issue because there is no reliable evidence that SEP components that reflect specific neural activity of the somatosensory thalamus can be recorded over the scalp.

Another novel result of this study is that neuroplastic changes related to pain occur at multiple levels of the somatosensory system not only in animals but also in humans. Large-scale reorganization at subcortical and cortical levels of the somatosensory pathway has been reported in monkeys that had undergone a therapeutic amputation of the hand (Florence and Kaas, 1995). An important implication of this result is that massive reorganization observed in the primary somatosensory cortex after major loss of peripheral input in part may reflect changes that occur subcortically (Florence and Kaas, 1995). In a similar vein, the increased excitability at subcortical levels observed in our study may induce an increased cortical excitability. Recent studies show that subcortical changes, for example at the thalamic level, are important substrates for cortical reorganization (Parker and Dostrovsky, 1999; Florence et al., 2000). However, the same studies have shown that the somatosensory cortex has refining functions on subcortical plasticity (Parker and Dostrovsky, 1999; Florence et al., 2000). This may be in line with our finding that there was no significant correlation between the increased amplitude of subcortical and cortical SEP components obtained in response to stimulation of the painful right thumb. Indeed, the finding may indicate that pain-related cortical plasticity is not a linear reflection of spinal and brainstem plasticity.

All in all, our results support previous evidence that the somatosensory system of adult humans may undergo major reorganization as a consequence of pathological modifications of sensory input (Elbert et al., 1994; Rossini et al., 1994; Yang et al., 1994; Flor et al., 1995; Tinazzi et al., 1997, 1998). The results also expand research suggesting that pain plays a crucial role in promoting neuroplasticity (Flor et al., 1995; 1997; Birbaumer et al., 1997) by showing, for the first time in humans, pain-related changes in neural activity at multiple sites of the somatosensory system.

\section{REFERENCES}

Allison T, McCarthy G, Wood CC, Jones SJ (1991) Potentials evoked in human and monkey cerebral cortex by stimulation of the median nerve. A review of scalp and intracranial recordings. Brain 114:2465-2503.

Birbaumer N, Lutzenberger W, Montoya P, Larbig W, Unertl K, Topfner S, Grood W, Taub E, Flor H (1997) Effects of regional anesthesia on phantom limb pain are mirrored in changes in cortical reorganization. J Neurosci 17:5503-5508.

Coderre TJ, Katz J, Vaccarino AL, Melzack R (1993) Contribution of central neuroplasticity to pathological pain: review of clinical and experimental evidence. Pain 52:259-285.

Davis KD, Kiss ZH, Luo L, Tasker RR, Lozano AM, Dostrovsky JO (1998) Phantom sensations generated by thalamic microstimulation. Nature 391:385-387.

Desmedt JE, Cheron G (1981) Prevertebral (oesophageal) recording of subcortical somatosensory evoked potentials in man: the spinal P13 component and the dual nature of the spinal generators. Electroencephalogr Clin Neurophysiol 52:257-276.

Desmedt JE, Nguyen TH, Bourguet M (1987) Bit-mapped colour imaging of human evoked potentials with reference to the N20, P22, P27, and N30 somatosensory components. Electroencephalogr Clin Neurophysiol 68:1-19.

Dougherty PM, Willis WD (1992) Enhanced responses of spinothalamic tract neurons to excitatory amino acids accompany capsaicin-induced sensitization in the monkey. J Neurosci 12:883-894.

Elbert T, Flor H, Birbaumer N, Knecht S, Hampson S, Larbig W, Taub E
(1994) Extensive reorganization of the somatosensory cortex in adult humans after nervous system injury. NeuroReport 5:2593-2597.

Faggin BM, Nguyen KT, Nicolelis MA (1997) Immediate and simultaneous sensory reorganization at cortical and subcortical levels of the somatosensory system. Proc Natl Acad Sci USA 94:9428-9433.

Flor H, Elbert T, Knecht S, Wienbruch C, Pantev C, Birbaumer N, Larbig W, Taub E (1995) Phantom-limb pain as a perceptual correlate of cortical reorganization following arm amputation. Nature 375:482-484.

Flor H, Braun C, Elbert T, Birbaumer N (1997) Extensive reorganization of primary somatosensory cortex in chronic back pain patients. Neurosci Lett 224:5-8.

Florence SL, Kaas JH (1995) Large-scale reorganization at multiple levels of the somatosensory pathway follows therapeutic amputation of the hand in monkeys. J Neurosci 15:8083-8095.

Florence SL, Hackett TA, Strata F (2000) Thalamic and cortical contributions to neural plasticity after limb amputation. J Neurophysiol 83:3154-3159.

Guilbaud G, Peschanski M, Briand A, Gautron M (1986) The organization of spinal pathways to ventrobasal thalamus in an experimental model of pain (the arthritic rat). An electrophysiological study. Pain 26:301-312.

Hoppenfield S (1976) Physical examination of the spine and extremities. New York: Appleton-Century Crofts.

Jain N, Florence SL, Qi HX, Kaas JH (2000) Growth of new brainstem connections in adult monkeys with massive sensory loss. Proc Natl Acad Sci USA 97:5546-5550.

Katz DB, Simon SA, Moody A, Nicolelis MA (1999) Simultaneous reorganization in thalamocortical ensembles evolves over several hours after perioral capsaicin injections. J Neurophysiol 82:963-977.

Kenshalo Jr DR, Leonard RB, Chung JM, Willis WD (1979) Responses of primate spinothalamic neurons to graded and to repeated noxious heat stimuli. J Neurophysiol 42:1370-1389.

Kenshalo Jr DR, Leonard RB, Chung JM, Willis WD (1982) Facilitation of the responses of primate spinothalmic cells to cold and mechanical stimuli by noxious heating of the skin. Pain 12:141-152.

Kimura J (1989) Electrodiagnosis in diseases of nerve and muscle: principles and practice, Ed 2. Philadelphia: Davis.

Knecht S, Soros P, Gurtler S, Imai T, Ringelstein EB, Henningsen H (1998) Phantom sensations following acute pain. Pain 77:209-213.

Lamour Y, Guilbaud G, Willer JC (1983) Altered properties and laminar distribution of neuronal responses to peripheral stimulation in the SmI cortex of the arthritic rat. Brain Res 273:183-187.

Maiani G, Sanavio E (1985) Semantics of pain in Italy: the Italian version of the McGill Pain Questionnaire. Pain 22:399-405.

Mauguière F, Desmedt JE (1988) Thalamic pain syndrome of DejerineRoussy. Differentiation of four subtypes assisted by somatosensory evoked potentials data. Arch Neurol 45:1312-1320.

Mauguière F, Desmedt JE, Courjon J (1983) Astereognosis and dissociated loss of frontal or parietal components of somatosensory evoked potentials in hemispheric lesions. Detailed correlations with clinical signs and computerized tomographic scanning. Brain 106:271-311.

McMahon SB, Wall PD (1984) Receptive fields of rat lamina 1 projection cells move to incorporate a nearby region of injury. Pain 19:235-247.

Melzack R (1975) McGill Pain Questionnaire. Major properties and scoring methods. Pain 1:277-299.

Merzenich MM, Kaas JH, Wall JY, Nelson RJ, Sur M, Felleman DJ (1983a) Topographic reorganization of somatosensory cortical Areas 3b and 1 in adult monkeys following restricted deafferentation. Neuroscience 8:33-55.

Merzenich MM, Kaas JH, Wall JY, Sur M, Nelson RJ, Felleman DJ (1983b) Progression of change following median nerve section in the cortical representation of the hand in areas $3 b$ and 1 in adult owl and squirrel monkeys. Neuroscience 10:639-665.

Oldfield RC (1971) The assessment and analysis of handedness: the Edinburgh inventory. Neuropsychologia 9:97-113.

Parker JL, Dostrovsky JO (1999) Cortical involvement in the induction, but not expression, of thalamic plasticity. J Neurosci 19:8623-8629.

Perl ER, Kumazawa T, Lynn B, Kenins P (1976) Sensitization of high threshold receptors with unmyelinated (C) afferent fibers. Prog Brain Res 43:263-277.

Pettit MJ, Schwark HD (1993) Receptive field organization in dorsal column nuclei during temporary denervation. Science 262:2054-2056.

Pons TP, Garraghty PE, Ommaya AK, Kaas JH, Taub E, Mishkin M (1991) Massive cortical reorganization after sensory deafferentation in adult macaques. Science 252:1857-1860.

Price DD, Hayes RL, Ruda M, Dubner R (1978) Spatial and temporal transformations of input to spinothalamic tract neurons and their relation to somatic sensations. J Neurophysiol 41:933-947.

Rossini PM, Martino G, Narici L, Pasquarelli A, Peresson M, Pizzella V, Tecchio F, Torrioli G, Romani GL (1994) Short-term brain 'plasticity' in humans: transient finger representation changes in sensory cortex somatotopy following ischemic anesthesia. Brain Res 11:169-177.

Schimsheimer RJ, Ongerboer de Visser BW, Bour LJ, Kropveld D, Van Ammers VCPJ (1988) Digital nerve somatosensory evoked potentials and flexor carpi radialis $\mathrm{H}$ reflexes in cervical disc protrusion and involvement of the sixth or seventh cervical root: relations to clinical and myelographic findings. Electroencephalogr Clin Neurophysiol 70:313-324. 
Simone DA, Sorkin LS, Oh U, Chung JM, Owens C, LaMotte RH, Willis WD (1991) Neurogenic hyperalgesia: central correlates in responses of spinothalamic tract neurons. J Neurophysiol 66:228-246.

Tinazzi M, Zanette G, Polo A, Volpato D, Manganotti P, Bonato C, Testoni R, Fiaschi A (1997) Transient deafferentation in humans induces rapid modulation of primary sensory cortex not associated with subcortical changes: a somatosensory evoked potential study. Neurosci Lett 223:21-24.

Tinazzi M, Zanette G, Volpato D, Testoni R, Bonato C, Manganotti P, Miniussi C, Fiaschi A (1998) Neurophysiological evidence of neuroplasticity at multiple levels of the somatosensory system in patients with carpal tunnel syndrome. Brain 121:1785-1794.
Tinazzi M, Priori A, Bertolasi L, Frasson E, Mauguiere F, Fiaschi A (2000) Abnormal central integration of a dual somatosensory input in dystonia: evidence for sensory overflow. Brain 123:42-50.

Woolf CJ, King AE (1990) Dynamic alterations in the cutaneous mechanoreceptive fields of dorsal horn neurons in the rat spinal cord. J Neurosci 10:2717-2726.

Yang TT, Gallen CC, Ramachandran J, Cobb S, Schwartz BJ, Bloom FE (1994) Non-invasive detection of cerebral plasticity in adult human somatosensory cortex. NeuroReport 5:701-704.

Yoss ER, Corbin KB, MacCarthy CS, Love JG (1957) Significance of symptoms and signs in localization of involved root in cervical disc protrusion. Neurology 7:673-683. 